\title{
Beliefs and Anxiety Levels Regarding Available COVID-19 Vaccine among Taif City Population, Saudi Arabia
}

\author{
Adnan A Mubaraki, MD ${ }^{* 1}$, Huda A AlEssa ${ }^{2}$, Safa K Almashyakhi ${ }^{2}$, Razan F Alwagdani ${ }^{2}$, Nada A Almalki ${ }^{2}$, \\ Aeshah D Alrabie ${ }^{2}$
}

${ }^{1}$ Department of Medicine, Faculty of Medicine, Taif University, Taif, Saudi Arabia

${ }^{2}$ College of Medicine, Taif University, Taif, Saudi Arabia

*Corresponding author: Dr. Huda A AlEssa; hudaaleisa@gmail.com

Received 09 August 2021;

Accepted 23 August 2021;

Published 02 September 2021

\begin{abstract}
Background: The development of a COVID-19 vaccine is seen as a critical strategy for bringing the pandemic to an end. Understanding the main determinants that influence the community's preferences and demands for a potential vaccine may aid in the development of strategies to improve the global vaccination program. Methods: This is a cross-sectional online self-administered questionnaire study that was distributed in Taif city, Saudi Arabia between March 2021 to June 2021. The survey included socio-demographic data, beliefs toward COVID-19 vaccination, barriers associated with acceptance of COVID-19 vaccination and the last part about generalized anxiety disorder scale. $\underline{\text { Results: }}$ It was reported that $25.6 \%$ of the participants had taken at least one dose of the COVID-19 vaccine (COV), and $39.8 \%$ are planning to take it. Regarding beliefs and perceptions related to $\mathrm{COV}, 44.3 \%$ had demonstrated positive beliefs and $55.7 \%$ had negative beliefs. The analysis showed that $59.7 \%$ agreed that $\mathrm{COV}$ is safe, and $57.8 \%$ believed that it is effective. It was found that $53.3 \%$ of the participants were concerned about the vaccine's side effects, and only $9.8 \%$ believed that the COVID-19 vaccination is a conspiracy. When we assessed the relationship of attitudes with sociodemographic characteristics of the participants, males, Saudi nationality, singles, higher qualifications, unemployment, and students showed more positive attitudes than the rest. Conclusion: Our research findings show that there is an association between planning to take the vaccine and positive attitudes toward vaccine safety and effectiveness among the Taif City population These results could help the government, ministry of health, health practitioners, and other health organizations to more accurately tailor messages around COVID-19 vaccine programs.
\end{abstract}

Keywords: COVID-19, Vaccine, beliefs, anxiety, awareness, Taif

\section{Introduction}

Emerging and re-emerging infectious diseases pose a constant danger to humanity. The COVID-19 pandemic is the most recent manifestation of this threat ${ }^{[1]}$. More than 10 million COVID-19 cases have been confirmed worldwide, and in Saudi Arabia 341,495 cases have been confirmed ${ }^{[2,3]}$. Respiratory illness, which includes a productive cough, dyspnea, sore throat, and headache, result in mild signs and symptoms ${ }^{[4]}$. Because there are no specific antiviral treatment options at this time, disease prevention remains the most effective way to stop the virus from spreading. Most of the preventive measures focus on social and physical distancing. Since it spreads by droplets, staying away from crowded areas and keeping a healthy distance from others are the most important preventive measures ${ }^{[1]}$. Efforts to eradicate the virus would also fail in the long end because new susceptible hosts are continuously provided by newly infected persons and the fading immunity of previously infected persons. The long-term durability of COVID19 immunity has yet to be determined ${ }^{[5]}$. In addition, vaccines have the potential to improve population immunity, reduce serious illnesses, and alleviate the current health crisis ${ }^{[4]}$. Acceptance of the vaccine depends on the vaccine's effectiveness and efficacy, suspicion of the health system, vaccine side effects, a lack of community knowledge regarding vaccine-preventable illnesses, and misconceptions about the vaccine's necessity, which are factors that must be considered ${ }^{[6-10]}$. If there is already a misconception regarding vaccination, public health will be jeopardized ${ }^{[3]}$. Because such information sources have the potential to influence people's approval or rejection of COVID-19 vaccines, it is critical to disseminate transparent and truthful information regarding vaccine safety and effectiveness to gain the confidence of the public ${ }^{[11]}$. It is also critical for the success of any future national immunization program to increase knowledge about the resources that people use to learn about COVID-19 vaccines ${ }^{[12]}$. A previous 
study in Saudi Arabia showed only $44.7 \%$ are accepting COVID19 vaccination if available, whereas $55.3 \%$ admitted hesitancy. The majority of vaccine refusers are concerned about the side effects ${ }^{[2]}$. Another study was done of general population in four major cities in Saudi Arabia, and it showed that $64.7 \%$ are considering having the COVID-19 vaccine, whereas $7.0 \%$ refused to take it, whereas $28.2 \%$ are not sure about it ${ }^{[3]}$. The acceptance of the COVID-19 vaccine among college students in South Carolina was found to be influenced by knowledge services. Students largely trust scientists $(83 \%)$, followed by healthcare providers $(74 \%)$ and health agencies $(70 \%)^{[13]}$. A group from China showed that the levels of anxiety and stress are lower when hand hygiene and other health protection practices were implemented ${ }^{[14]}$. These results underscore the value of urging the public to partake in such actions not only to reduce the risk of infection but also to reduce the fear associated with COVID-19 ${ }^{[12]}$. The few studies conducted in Saudi Arabia have only reported the beliefs and barriers associated with COVID-19 vaccination among the general population in the country. This study intended to measure beliefs and anxiety levels regarding the available COVID-19 vaccine among the Taif City population in Saudi Arabia.

\section{Materials and Methods}

A cross-sectional study was done in Taif City, Saudi Arabia, to determine community beliefs and anxiety about the current COVID-19 vaccine. The sample included a total number of 1200 participants. It was carried out from March 2021 to June 2021. All communities over the age of 18 were included with no specific exclusion criteria. It was done by the collection of data via an electronic questionnaire which was designed by the authors based upon a review of the literature. It involved four main parts: The first part included sociodemographic data such as age, nationality, education level, occupation. The second part included questions to assess their beliefs toward the COVID-19 vaccination. The third part evaluates the participant's barriers associated with acceptance of COVID-19 vaccination. The last part included validated questions about items generalized anxiety disorder scale. This study was approved by the Research Ethics Committee of The Health Affairs in Taif (IRB: HAO-02-T-105). Statistical analysis was done using SPSS ver23 (IBM corp. The USA) by an independent biostatistician. Categorical variables were analyzed using Pearson's Chi-square test. Continuous variables obtained were expressed as mean and standard deviation. The significance value ( $\mathrm{p}$-value) $<0.05$ is considered statistically significant.

\section{Results}

The online survey had 1200 completed responses included for the analysis that had $25.3 \%$ of males and $74.8 \%$ of the female participants. The detailed sociodemographic characteristics are given in Table 1 . In our study, it was reported by $25.6 \%(n=307)$ participants that they had taken at least one dose of the COVID-19 vaccine $(\mathrm{COV})$, and $39.8 \%$ are planning to take it. There were ten items in the questionnaire that measured the beliefs and perceptions related to the COVID-19 vaccine. The responses related to beliefs and attitudes towards COV are given in Table 2 . Scores were allotted based on the responses (for good "1" and poor "0") and were added to get a total score, which was then categorized into positive $(>=80 \%)$ and negative beliefs. $(<80 \%)$ The analysis showed that $44.3 \% \quad(n=532)$ had demonstrated positive beliefs and $55.7 \%(\mathrm{n}=668)$ negative beliefs.

When we assessed the relationship of beliefs regarding $\mathrm{COV}$ of the participants with their sociodemographic characteristics, it was found that only gender of the participants had a statistically significant association, where male participants showed more positive beliefs $(53.5 \%)$ than females $(41.2 \%)$ (p $<0.001$ ), where other sociodemographic characteristics such as age, Nationality, Marital status, Educational qualification, and Employment didn't show any statistically significant association [Table 3]. The analysis showed that $59.7 \%$ agreed that COV is safe, and $57.8 \%$ believed that it is effective. It was found that $53.3 \%(n=640)$ of the participants were concerned about the vaccine's side effects, and only $9.8 \%$ believed that the COVID-19 vaccination is a conspiracy. It was reported by $11.3 \%$ of the participants that they don't need vaccines as they do all preventive things like washing hands, wearing masks and gloves in the right manner [Table 2].

The assessment of attitude towards COV showed that $24.8 \%$ reported that they would take the vaccine if their physician recommended it, and $55.3 \%$ told that they would take the vaccine only if more research studies showed it is safe and effective. It was reported by $17.2 \%$ of the participants that they would take the vaccine only if the government made it compulsory, and $12.2 \%$ told they would take it only if their job or workplace demands it [Table 2]. When we assessed the relationship of attitudes with $\mathrm{s}$ sociodemographic characteristics of the participants, there was a statistically significant association observed with nationality, marital status, educational qualification, and Employment. It was observed that Saudi citizens (32.5\%) showed a comparatively more positive attitude towards COVID-19 vaccination than non-Saudis $(6.7 \%)(\mathrm{p}=0.003)$. Single participant showed a comparatively more positive attitude towards vaccines than those who were married $(30.7 \%)$ and divorced/widowed $(9.4 \%) \quad(p=0.012)$. When the attitude towards COV was compared between different educational qualifications, it was found that participants who had a university degree or higher qualification had shown a comparatively more positive attitude $(33.6 \%)$ than those who had less qualification $(\mathrm{p}=0.033)$. It was also found that unemployed and students showed comparatively more positive attitudes than those who are employed $(\mathrm{p}=0.003)$ [Table 4].

Table 1: Sociodemographic details

\begin{tabular}{|c|c|c|c|}
\hline & & Frequency & Percent \\
\hline \multirow[t]{3}{*}{ Age } & $15-39$ & 975 & 81.3 \\
\hline & $40-59$ & 209 & 17.4 \\
\hline & More than 60 & 16 & 1.3 \\
\hline \multirow[t]{2}{*}{ Gender } & Male & 303 & 25.3 \\
\hline & Female & 897 & 74.8 \\
\hline \multirow[t]{2}{*}{ Nationality } & Saudi & 1170 & 97.5 \\
\hline & Non saudi & 30 & 2.5 \\
\hline \multirow[t]{2}{*}{ Marital status } & Single & 660 & 55.0 \\
\hline & Married & 508 & 42.3 \\
\hline
\end{tabular}


International Journal of Innovative Research in Medical Science (IJIRMS)

\begin{tabular}{|c|c|c|c|}
\hline & Widowed /divorce & 32 & 2.7 \\
\hline \multirow[t]{4}{*}{ Educational qualification } & Illiterate & 7 & .6 \\
\hline & Primary school & 29 & 2.4 \\
\hline & Secondary /high school & 305 & 25.4 \\
\hline & University /higher education & 859 & 71.6 \\
\hline \multirow[t]{4}{*}{ Employment } & Unemployed & 370 & 30.8 \\
\hline & Student & 442 & 36.8 \\
\hline & Governmental & 276 & 23.0 \\
\hline & Private & 112 & 9.3 \\
\hline \multirow[t]{9}{*}{ Chronic diseases } & Yes & 137 & 11.4 \\
\hline & No & 1063 & 88.6 \\
\hline & Diabetes & 32 & 23.4 \\
\hline & Hypertension & 18 & 13.1 \\
\hline & Cardiovascular & 7 & 5.1 \\
\hline & Neurological & 2 & 1.5 \\
\hline & Liver & 2 & 1.5 \\
\hline & Asthma & 16 & 11.7 \\
\hline & Other & 19 & 13.9 \\
\hline
\end{tabular}

Table 2: Responses to the questionnaire on COVID-19 vaccine

\begin{tabular}{|c|c|c|c|c|}
\hline & & Responses & $\mathbf{N}$ & $\%$ \\
\hline \multirow{23}{*}{ 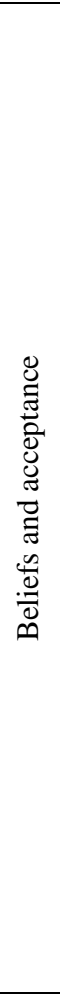 } & \multirow[t]{3}{*}{ COVID-19 vaccination safe } & Yes & 716 & 59.7 \\
\hline & & No & 97 & 8.1 \\
\hline & & Not sure & 387 & 32.3 \\
\hline & \multirow[t]{3}{*}{ COVID-19 vaccination effective } & Yes & 694 & 57.8 \\
\hline & & No & 81 & 6.8 \\
\hline & & Not sure & 425 & 35.4 \\
\hline & \multirow[t]{3}{*}{ The best way to complications of COVID-19 is by being vaccinated. } & Yes & 763 & 63.6 \\
\hline & & No & 159 & 13.3 \\
\hline & & Not sure & 278 & 23.2 \\
\hline & \multirow[t]{2}{*}{ There is no barrier to get vaccinated } & Yes & 391 & 32.6 \\
\hline & & No & 809 & 67.4 \\
\hline & \multirow[t]{2}{*}{ Concerned about the vaccine side effects } & Yes & 640 & 53.3 \\
\hline & & No & 560 & 46.7 \\
\hline & \multirow[t]{2}{*}{ Don't believe that the vaccine will stop the infection } & Yes & 147 & 12.3 \\
\hline & & No & 1053 & 87.8 \\
\hline & \multirow[t]{2}{*}{ COVID-19 vaccination is a conspiracy } & Yes & 118 & 9.8 \\
\hline & & No & 1082 & 90.2 \\
\hline & \multirow{2}{*}{$\begin{array}{l}\text { Don't need the vaccine because I do all the right things. I wash my hands and wear } \\
\text { a mask and gloves }\end{array}$} & Yes & 135 & 11.3 \\
\hline & & No & 1065 & 88.8 \\
\hline & \multirow[t]{2}{*}{ Don't need the vaccine because I am young and healthy } & Yes & 70 & 5.8 \\
\hline & & No & 1130 & 94.2 \\
\hline & \multirow[t]{2}{*}{ Don’t like needles } & Yes & 155 & 12.9 \\
\hline & & No & 1045 & 87.1 \\
\hline \multirow{14}{*}{ 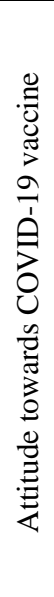 } & \multirow[t]{2}{*}{ If my physician recommended it to me } & Yes & 298 & 24.8 \\
\hline & & No & 902 & 75.2 \\
\hline & \multirow[t]{2}{*}{ If I know that more studies showed that the vaccine is safe and effective } & Yes & 663 & 55.3 \\
\hline & & No & 537 & 44.8 \\
\hline & \multirow[t]{2}{*}{ If it was compulsory by the government (MOH) } & Yes & 206 & 17.2 \\
\hline & & No & 994 & 82.8 \\
\hline & \multirow[t]{2}{*}{ If it was mandatory by my job } & Yes & 146 & 12.2 \\
\hline & & No & 1054 & 87.8 \\
\hline & \multirow[t]{2}{*}{ If my family or friends got vaccinated } & Yes & 122 & 10.2 \\
\hline & & No & 1078 & 89.8 \\
\hline & \multirow[t]{2}{*}{ If there is a way other than injection } & Yes & 80 & 6.7 \\
\hline & & No & 1120 & 93.3 \\
\hline & \multirow[t]{2}{*}{ I would not take it in anyway } & Yes & 86 & 7.2 \\
\hline & & No & 1114 & 92.8 \\
\hline
\end{tabular}


Table 3: Beliefs and perceptions towards COVID-19 vaccine and its relationship with sociodemographic characteristics

\begin{tabular}{|c|c|c|c|c|}
\hline & & \multicolumn{2}{|c|}{ Belief and Perceptions } & \multirow[t]{2}{*}{ P value } \\
\hline & & Positive & Negative & \\
\hline \multirow[t]{3}{*}{ Age } & $15-39$ & $441(45.2 \%)$ & $534(54.8 \%)$ & \multirow[t]{3}{*}{0.724} \\
\hline & $40-59$ & $84(40.2 \%)$ & $125(59.8 \%)$ & \\
\hline & $>60$ & $7(43.8 \%)$ & $9(56.3 \%)$ & \\
\hline \multirow[t]{2}{*}{ Gender } & Male & $162(53.5 \%)$ & $141(46.5 \%)$ & \multirow[t]{2}{*}{$<0.001^{*}$} \\
\hline & Female & $370(41.2 \%)$ & $527(58.8 \%)$ & \\
\hline \multirow[t]{2}{*}{ Nationality } & Saudi & $523(44.7 \%)$ & $647(55.3 \%)$ & \multirow[t]{2}{*}{0.109} \\
\hline & Non -Saudi & $9(30.0 \%)$ & $21(70.0 \%)$ & \\
\hline \multirow[t]{3}{*}{ Marital status } & Single & $299(45.3 \%)$ & $361(54.7 \%)$ & \multirow[t]{3}{*}{0.724} \\
\hline & Married & $220(43.3 \%)$ & $288(56.7 \%)$ & \\
\hline & Widowed /divorced & $13(40.6 \%)$ & $19(59.4 \%)$ & \\
\hline \multirow[t]{4}{*}{ Educational qualification } & Illiterate & $4(57.1 \%)$ & $3(42.9 \%)$ & \multirow[t]{4}{*}{0.890} \\
\hline & Primary school & $12(41.4 \%)$ & $17(58.6 \%)$ & \\
\hline & Secondary /high school & $137(44.9 \%)$ & $168(55.1 \%)$ & \\
\hline & University /higher education & $379(44.1 \%)$ & $480(55.9 \%)$ & \\
\hline \multirow[t]{4}{*}{ Employment } & Unemployed & $173(46.8 \%)$ & $197(53.2 \%)$ & \multirow[t]{4}{*}{0.457} \\
\hline & Student & $189(42.8 \%)$ & $253(57.2 \%)$ & \\
\hline & Governmental & $116(42.0 \%)$ & $160(58.0 \%)$ & \\
\hline & Private & $54(48.2 \%)$ & $58(51.8 \%)$ & \\
\hline
\end{tabular}

Table 4: Attitudes towards COVID-19 vaccine and its relationship with sociodemographic characteristics

\begin{tabular}{|c|c|c|c|c|}
\hline & & \multicolumn{2}{|l|}{ Attitudes } & \multirow[t]{2}{*}{ P value } \\
\hline & & Positive & Negative & \\
\hline \multirow[t]{3}{*}{ Age } & $15-39$ & $307(31.5 \%)$ & $668(68.5 \%)$ & \multirow[t]{3}{*}{0.563} \\
\hline & $40-59$ & $68(32.5 \%)$ & $141(67.5 \%)$ & \\
\hline & $>60$ & $7(43.8 \%)$ & $9(56.3 \%)$ & \\
\hline \multirow[t]{2}{*}{ Gender } & Male & $88(29.0 \%)$ & $215(71.0 \%)$ & \multirow[t]{2}{*}{0.228} \\
\hline & Female & $294(32.8 \%)$ & $603(67.2 \%)$ & \\
\hline \multirow[t]{2}{*}{ Nationality } & Saudi & $380(32.5 \%)$ & $790(67.5 \%)$ & \multirow[t]{2}{*}{0.003} \\
\hline & Non -saudi & $2(6.7 \%)$ & $28(93.3 \%)$ & \\
\hline \multirow[t]{3}{*}{ Marital status } & Single & $223(33.8 \%)$ & $437(66.2 \%)$ & \multirow[t]{3}{*}{$0.012 *$} \\
\hline & Married & $156(30.7 \%)$ & $352(69.3 \%)$ & \\
\hline & Widowed /divorced & $3(9.4 \%)$ & $29(90.6 \%)$ & \\
\hline \multirow[t]{4}{*}{ Educational qualification } & Illiterate & $2(28.6 \%)$ & $5(71.4 \%)$ & \multirow[t]{4}{*}{$0.033 *$} \\
\hline & Primary school & $3(10.3 \%)$ & $26(89.7 \%)$ & \\
\hline & Secondary /high school & $88(28.9 \%)$ & $217(71.1 \%)$ & \\
\hline & University /higher education & $289(33.6 \%)$ & $570(66.4 \%)$ & \\
\hline \multirow[t]{4}{*}{ Employment } & Unemployed & $130(35.1 \%)$ & $240(64.9 \%)$ & \multirow[t]{4}{*}{$0.003 *$} \\
\hline & Student & $154(34.8 \%)$ & $288(65.2 \%)$ & \\
\hline & Governmental & $76(27.5 \%)$ & $200(72.5 \%)$ & \\
\hline & Private & $22(19.6 \%)$ & $90(80.4 \%)$ & \\
\hline
\end{tabular}

* Statistically significant

Table 5: Anxiety towards COVID-19 vaccine and its relationship with sociodemographic characteristics

\begin{tabular}{|c|c|c|c|c|c|c|}
\hline & & \multicolumn{4}{|l|}{ Anxiety level } & \multirow[t]{2}{*}{$\mathrm{P}$ value } \\
\hline & & No anxiety & Mild & Moderate & Severe & \\
\hline \multirow{3}{*}{$\underset{\&}{\infty}$} & $15-39$ & $741(76.0 \%)$ & $173(17.7 \%)$ & $54(5.5 \%)$ & $7(0.7 \%)$ & \multirow[t]{3}{*}{$<0.001 *$} \\
\hline & $40-59$ & $139(66.5 \%)$ & $44(21.1 \%)$ & $18(8.6 \%)$ & $8(3.8 \%)$ & \\
\hline & $>60$ & $7(43.8 \%)$ & $6(37.5 \%)$ & $1(6.3 \%)$ & $2(12.5 \%)$ & \\
\hline \multirow{2}{*}{ 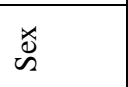 } & Male & $251(82.8 \%)$ & $39(12.9 \%)$ & $10(3.3 \%)$ & $3(1.0 \%)$ & \multirow[t]{2}{*}{$0.001^{*}$} \\
\hline & Female & $636(70.9 \%)$ & $184(20.5 \%)$ & $63(7.0 \%)$ & $14(1.6 \%)$ & \\
\hline \multirow{2}{*}{ 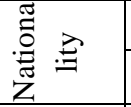 } & Saudi & $867(74.1 \%)$ & $217(18.5 \%)$ & $69(5.9 \%)$ & $17(1.5 \%)$ & \multirow[t]{2}{*}{0.341} \\
\hline & Non-saudi & $20(66.7 \%)$ & $6(20.0 \%)$ & $4(13.3 \%)$ & $0(0.0 \%)$ & \\
\hline \multirow{3}{*}{ 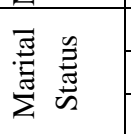 } & Single & $497(75.3 \%)$ & $118(17.9 \%)$ & $41(6.2 \%)$ & $4(0.6 \%)$ & \multirow[t]{3}{*}{0.104} \\
\hline & Married & $371(73.0 \%)$ & $96(18.9 \%)$ & $29(5.7 \%)$ & $12(2.4 \%)$ & \\
\hline & Widowed /divorce & $19(59.4 \%)$ & $9(28.1 \%)$ & $3(9.4 \%)$ & $1(3.1 \%)$ & \\
\hline \multirow{2}{*}{ 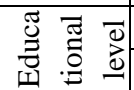 } & Illiterate & $6(85.7 \%)$ & $0(0.0 \%)$ & $1(14.3 \%)$ & $0(0.0 \%)$ & \multirow[t]{2}{*}{0.773} \\
\hline & Primary school & $19(65.5 \%)$ & $9(31.0 \%)$ & $1(3.4 \%)$ & $0(0.0 \%)$ & \\
\hline
\end{tabular}




\begin{tabular}{|c|c|c|c|c|c|c|}
\hline & Secondary/high school & $227(74.4 \%)$ & $57(18.7 \%)$ & $17(5.6 \%)$ & $4(1.3 \%)$ & \\
\hline & University /higher & $635(73.9 \%)$ & $157(18.3 \%)$ & $54(6.3 \%)$ & $13(1.5 \%)$ & \\
\hline \multirow{4}{*}{ 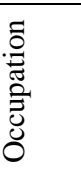 } & Unemployed & $262(70.8 \%)$ & $84(22.7 \%)$ & $18(4.9 \%)$ & $6(1.6 \%)$ & \multirow[t]{4}{*}{0.174} \\
\hline & Student & $339(76.7 \%)$ & $70(15.8 \%)$ & $29(6.6 \%)$ & $4(0.9 \%)$ & \\
\hline & Governmental & $200(72.5 \%)$ & $55(19.9 \%)$ & $16(5.8 \%)$ & $5(1.8 \%)$ & \\
\hline & Private & $86(76.8 \%)$ & $14(12.5 \%)$ & $10(8.9 \%)$ & $2(1.8 \%)$ & \\
\hline \multirow{2}{*}{ 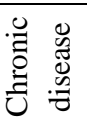 } & Yes & $86(62.8 \%)$ & $37(27.0 \%)$ & $10(7.3 \%)$ & $4(2.9 \%)$ & \multirow[t]{2}{*}{$0.010^{*}$} \\
\hline & No & $801(75.4 \%)$ & $186(17.5 \%)$ & $63(5.9 \%)$ & $13(1.2 \%)$ & \\
\hline
\end{tabular}

* Statistically significant

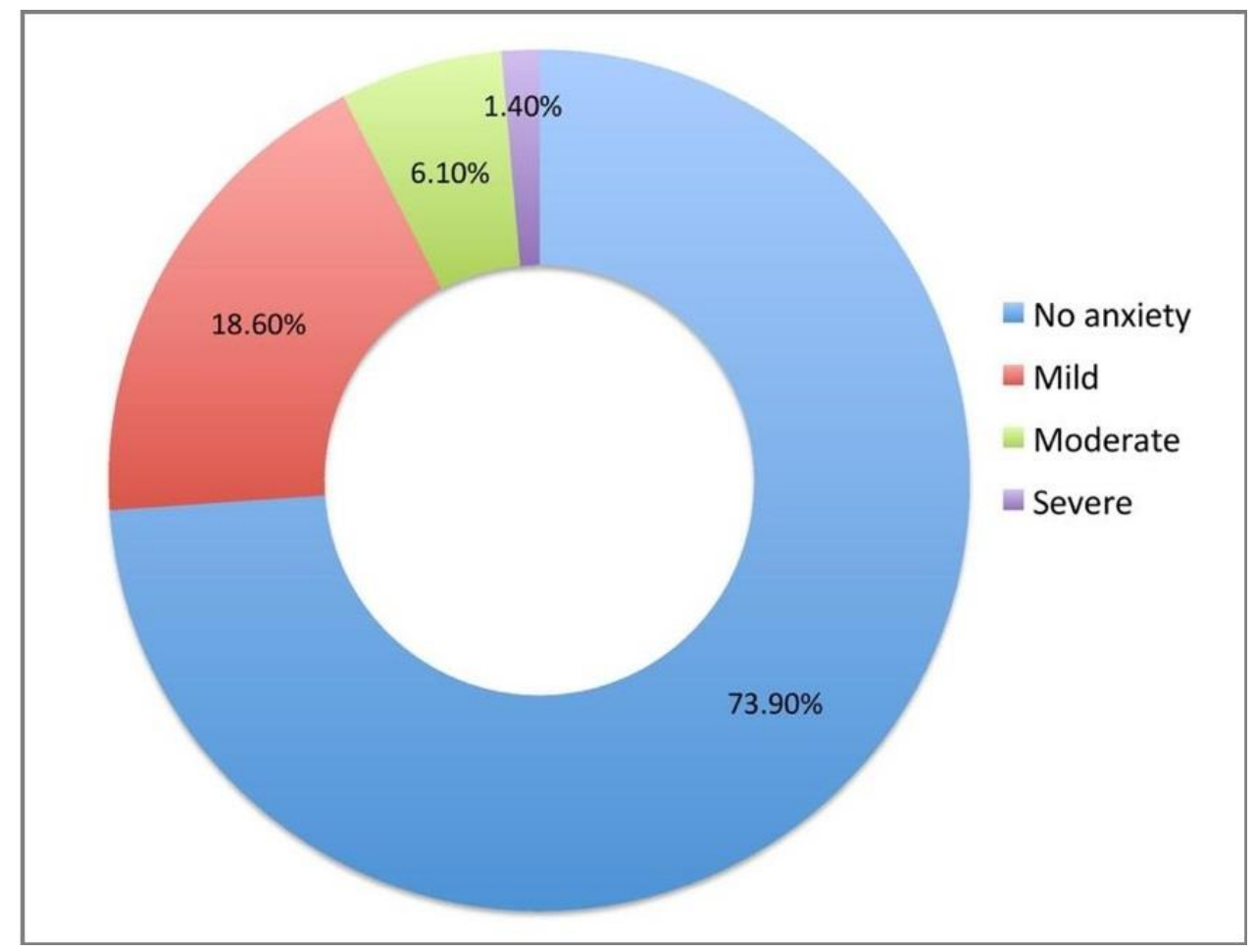

Figure 1: Reported anxiety levels regarding COVID-19 vaccine

\section{Discussion}

This cross-sectional study sought to explore the beliefs, acceptance, and attitudes towards vaccination against SARS-CoV2 among Taif City residents. In Saudi Arabia, the campaign for the COVID-19 vaccine was launched on December 17, 2020, after the first batch of Pfizer-BioNTech vaccine arrived in the Kingdom that was approved by the Saudi Food and Drug Authority (SFDA) (15). As of May 8, 2021, more than 10.1 million doses have been given .The findings of this web-based self-administered questionnaire showed that approximately $26 \%$ of the participants had taken at least one dose of the COVID-19 vaccine, and nearly $40 \%$ of them were planning to take it. It was found that $7.2 \%$ reported that they are not going to take regardless ${ }^{[16]}$. A study conducted in China reported that $72.5 \%$ of participants from the general population had intended to take the COVID-19 vaccine ${ }^{[17]}$, and another study in the United States reported an acceptance rate of $80 \%{ }^{[18]}$. The reported rate for 'no to COVID-19' agrees with another study performed by Al-Mohaithef and Padhi, which was done before the availability of the COVID-19 vaccine in the Kingdom ${ }^{[3]}$. The acceptance rate for the COVID-19 vaccine in our study (39.8\%) was less compared to that in other countries such as China (90\%), Brazil (86\%), the United States (75.4\%), India (74.3\%), and Russia $(55 \%)^{[18]}$. Previous studies done in the Kingdom regarding vaccine acceptance for different diseases have reported a comparatively good acceptance rate for seasonal influenza ${ }^{[19,20]}$, whereas a poor acceptance rate has been reported for the H1N1 vaccine ${ }^{[21]}$. The lowered acceptance rate in our study could be due to rumors spreading on social media and some misconceptions about the vaccine which include but are not limited to the belief that there is an electronic chip in the vaccine, that it affects fertility and other mistaken beliefs about side effects.

The current study findings showed that approximately $60 \%$ of the participants believed that the COVID-19 vaccine is safe and approximately $58 \%$ believed that it is effective. However, positive beliefs towards COVID-19 vaccine intake were found in only $44.3 \%$ of participants. A study done in the United States reported that approximately $63 \%$ of the participants were worried about the side effects of the COVID-19 vaccine ${ }^{[22]}$. There is a cloud of hesitancy regarding the safety of the COVID-19 vaccine. Many COVID-19 vaccine trials have been paused due to detected side effects, and this could be one of the major concerns among the community. Additionally, a global phenomenon of anti-vaccination campaigns exists on social media that spread fake, fabricated, and misleading information against vaccination. This could be another reason for people having a negative viewpoint regarding the COVID-19 vaccine. It has been reported that people who do not believe in any conspiracy or untrue information regarding the COVID-19 vaccine were more likely to get vaccinated ${ }^{[23]}$. We found that male participants demonstrated comparatively better positive attitudes towards the COVID-19 vaccine. A survey was 
done in 19 countries by Lazarus et al, who reported that women are more likely to accept vaccines than men ${ }^{[24]}$. These findings reflect women's greater level of empathy and care towards the safety of their families. Our findings supported those women have exhibited comparatively more positive attitudes than men have even though there was no statistically significant difference between the two genders. Those who were single had better positive attitudes towards the COVID-19 vaccine than those who were married or divorced. The study also shows that individuals with a higher educational qualification, such as a bachelor's degree or more were more likely to accept vaccines than those having lesser qualifications. These findings could help the government, Ministry of Health, health professionals, and other health organizations to target messaging more effectively for COVID- 19 vaccination programs.

In our study, approximately $73.9 \%$ did not have any anxiety regarding taking by COVID-19 vaccine, whereas severe anxiety scores were observed for $1.4 \%$ of the participants. The anxiety was comparatively more in people over the age of 40 years, females, and those with chronic diseases. According to the Centers for Disease Control and Prevention (CDC), certain chronic diseases such as COPD (chronic obstructive pulmonary disease), asthma (moderate-to-severe), interstitial lung disease, cystic fibrosis, pulmonary hypertension, diabetes, heart conditions (such as heart failure, coronary artery disease, cardiomyopathies or hypertension), renal diseases, and immunodeficiency conditions are more likely to get severely ill from COVID-19. Thus COVID19 vaccines are recommended for and can be administered to most people with these underlying medical conditions ${ }^{[25,26]}$. It has been reported by Barry et al. that those who were willing to receive the vaccine had significantly higher general anxiety levels ${ }^{[5]}$. Additionally, it is remarkable that COVID-19 related anxiety and health-related fears may have also influenced people's anxiety regarding vaccine acceptance, which could lead to a higher willingness to take it. Bendau et al. reported that higher anxiety related to COVID-19 and fear related to health would increase the acceptance rate of the COVID-19 vaccine ${ }^{[27]}$. The findings of this study show that to improve attitudes towards COVID-19 vaccination, we need to understand the physical, social and emotional impacts that the disease has had on individuals, and people should be educated regarding the efficacy and safety issues of the vaccine. A study conducted in the United States reported that giving access to health information would increase the acceptance rate of vaccines ${ }^{[28]}$.

Limitations of our study include the sample size and the web-based survey which may not allow the generalization of findings. However, considering the pandemic situation the webbased survey could prove to be best and appropriate to measure the beliefs, attitudes, and anxiety of the COVID-19 vaccine. Responses were collected from only residents in Taif with a good response rate that may have shown some degree of representativeness. There could be a presence of response bias and social desirability bias due to the self-reported nature of the questionnaire.

\section{Conclusion}

Our research shows that there is an association between planning to take the vaccine and positive attitudes toward vaccine safety and effectiveness among the Taif City population. Additionally, we found that there is a strong correlation between educational qualification and vaccine acceptance. Nonetheless, there is a need to update the data on acceptance rate and anxiety levels regarding the COVID-19 vaccine as mass vaccination programs are underway in the Kingdom. Future research should consider other predictive factors that determine COVID-19 vaccine acceptance. These results could help the government, Ministry of Health, health practitioners, and other health organizations to more accurately tailor messages regarding COVID-19 vaccine programs.

\section{References}

[1] Sallam M, Dababseh D, Yaseen A, Al-Haidar A, Ababneh NA, Bakri FG, et al. Conspiracy Beliefs Are Associated with Lower Knowledge and Higher Anxiety Levels Regarding COVID-19 among Students at the University of Jordan. Int J Environ Res Public Health. 2020;17(14):4915.

[2] Magadmi RM, Kamel FO. Beliefs and barriers associated with COVID-19 vaccination among the general population in Saudi Arabia. BMC public health. 2021;21(1):1438.

[3] Al-Mohaithef M, Padhi BK. Determinants of COVID-19 Vaccine Acceptance in Saudi Arabia: A Web-Based National Survey. Journal of multidisciplinary healthcare. 2020;13:1657-63.

[4] Voysey M, Clemens SAC, Madhi SA, Weckx LY, Folegatti PM, Aley PK, et al. Safety and efficacy of the ChAdOx1 nCoV-19 vaccine (AZD1222) against SARSCoV-2: an interim analysis of four randomised controlled trials in Brazil, South Africa, and the UK. The Lancet. 2021;397(10269):99-111.

[5] Barry M, Temsah M-H, Alhuzaimi A, Alamro N, AlEyadhy A, Aljamaan F, et al. COVID-19 vaccine confidence and hesitancy among healthcare workers: a cross-sectional survey from a MERS-CoV experienced nation. Medrxiv. 2020.

[6] Larson HJ, Clarke RM, Jarrett C, Eckersberger E, Levine Z, Schulz WS, et al. Measuring trust in vaccination: A systematic review. Hum Vaccin Immunother. 2018;14(7):1599-609.

[7] Gidengil CA, Parker AM, Zikmund-Fisher BJ. Trends in risk perceptions and vaccination intentions: a longitudinal study of the first year of the H1N1 pandemic. American journal of public health. 2012;102(4):672-9.

[8] Xiao X, Wong RM. Vaccine hesitancy and perceived behavioral control: A meta-analysis. Vaccine. 2020;38(33):5131-8.

[9] Setbon M, Raude J. Factors in vaccination intention against the pandemic influenza A/H1N1. European Journal of Public Health. 2010;20(5):490-4.

[10] Halpin C, Reid B. Attitudes and beliefs of healthcare workers about influenza vaccination. Nursing older people. 2019.

[11] Siegrist M, Zingg A. The role of public trust during pandemics: Implications for crisis communication. European Psychologist. 2014;19(1):23-32.

[12] Mannan DKA, Farhana KM. Knowledge, attitude and acceptance of a COVID-19 vaccine: A global crosssectional study. International Research Journal of Business and Social Science. 2020;6(4).

[13] Qiao S, Friedman DB, Tam CC, Zeng C, Li X. Vaccine acceptance among college students in South Carolina: Do information sources and trust in information make a difference? medRxiv. 2020. 
[14] Wang C, Pan R, Wan X, Tan Y, Xu L, Ho CS, et al. Immediate Psychological Responses and Associated Factors during the Initial Stage of the 2019 Coronavirus Disease (COVID-19) Epidemic among the General Population in China. Int J Environ Res Public Health. 2020;17(5).

[15] Barry M, BaHammam AS. COVID-19 vaccine in the Kingdom of Saudi Arabia: A true operation warp speed. Journal of Nature and Science of Medicine. 2021;4(2):92.

[16] Roser M, Ritchie H, Ortiz-Ospina E, Hasell J. Coronavirus pandemic (COVID-19). Our world in data. 2020.

[17] Thunstrom L, Ashworth M, Finnoff D, Newbold S. Hesitancy towards a COVID-19 vaccine and prospects for herd immunity. Available at SSRN 3593098. 2020.

[18] Lazarus JV, Ratzan SC, Palayew A, Gostin LO, Larson HJ, Rabin K, et al. A global survey of potential acceptance of a COVID-19 vaccine. Nature medicine. 2021;27(2):225-8.

[19] Alotaibi FY, Alhetheel AF, Alluhaymid YM, Alshibani MG, Almuhaydili AO, Alhuqayl TA, et al. Influenza vaccine coverage, awareness, and beliefs regarding seasonal influenza vaccination among people aged 65 years and older in Central Saudi Arabia. Saudi medical journal. 2019;40(10):1013-8.

[20] Alqahtani AS, Althobaity HM, Al Aboud D, AbdelMoneim AS. Knowledge and attitudes of Saudi populations regarding seasonal influenza vaccination. Journal of infection and public health. 2017;10(6):897900 .
[21] Alsaleem MA. Acceptance of H1N1 vaccine among healthcare workers at primary healthcare centres in Abha, KSA. The Journal of the Egyptian Public Health Association. 2013;88(1):32-9.

[22] Pogue K, Jensen JL, Stancil CK, Ferguson DG, Hughes SJ, Mello EJ, et al. Influences on Attitudes Regarding Potential COVID-19 Vaccination in the United States. Vaccines. 2020;8(4).

[23] El-Elimat T, AbuAlSamen MM, Almomani BA, AlSawalha NA, Alali FQ. Acceptance and attitudes toward COVID-19 vaccines: A cross-sectional study from Jordan. PloS one. 2021;16(4):e0250555.

[24] Lazarus JV, Wyka K, Rauh L, Rabin K, Ratzan S, Gostin LO, et al. Hesitant or Not? The Association of Age, Gender, and Education with Potential Acceptance of a COVID-19 Vaccine: A Country-level Analysis. Journal of Health Communication. 2020;25(10):799-807.

[25] Team CC-R. Characteristics of Health Care Personnel with COVID-19 - United States, February 12-April 9, 2020. MMWR Morb Mortal Wkly Rep. 2020;69(15):477-81.

[26] Sanyaolu A, Okorie C, Marinkovic A, Patidar R, Younis $\mathrm{K}$, Desai P, et al. Comorbidity and its Impact on Patients with COVID-19. SN Compr Clin Med. 2020:1-8.

[27] Bendau A, Plag J, Petzold MB, Ströhle A. COVID-19 vaccine hesitancy and related fears and anxiety. International immunopharmacology. 2021;97:107724.

[28] Gatwood J, Shuvo S, Hohmeier KC, Hagemann T, Chiu $\mathrm{CY}$, Tong $\mathrm{R}$, et al. Pneumococcal vaccination in older adults: An initial analysis of social determinants of health and vaccine uptake. Vaccine. 2020;38(35):5607-17. 